\title{
Structural, Optical, Electrical, and Photoresponse Properties of Postannealed Sn-Doped ZnO Nanorods
}

\author{
Q. Humayun, M. Kashif, and U. Hashim \\ Nano Biochip Research Group, Institute of Nano Electronic Engineering (INEE), Universiti Malaysia Perlis (UniMAP), \\ 01000 Kangar, Perlis, Malaysia
}

Correspondence should be addressed to Q. Humayun; qhumayun2@gmail.com

Received 10 October 2013; Revised 22 November 2013; Accepted 28 November 2013

Academic Editor: Haibo Zeng

Copyright (C) 2013 Q. Humayun et al. This is an open access article distributed under the Creative Commons Attribution License, which permits unrestricted use, distribution, and reproduction in any medium, provided the original work is properly cited.

Tin $(\mathrm{Sn})$ doped $\mathrm{ZnO}$ nanorods were synthesized on glass substrate using a sol-gel method. The synthesized nanorods were postannealed at 150,350 , and $500^{\circ} \mathrm{C}$. The surface morphologies of $\mathrm{Sn}$-doped $\mathrm{ZnO}$ nanorods at different postannealing temperatures were studied using scanning electron microscope (SEM). XRD results show that as the postannealing temperature increased from $150^{\circ} \mathrm{C}$ to $500^{\circ} \mathrm{C}$, the $c$-axis orientation becomes stronger. Refractive indices and dielectric constants were calculated on the basis of different relationships by utilizing bandgap values. These bandgap values were obtained in terms of optical absorption by using a UV-Visible spectrophotometer. The enhancing effects of annealing temperatures on electrical properties were observed in terms of current-to-voltage measurements. Resistivity decreases as postannealing temperature increases from $150^{\circ} \mathrm{C}$ to $500^{\circ} \mathrm{C}$. Annealed samples were evaluated for UV-sensing application. The samples exhibit a responsivity of $1.7 \mathrm{~A} / \mathrm{W}$.

\section{Introduction}

Zinc oxide is an n-type semiconductor with bandgap energy of $3.37 \mathrm{eV}$ and large exciton binding energy of $\sim 60 \mathrm{meV}$. $\mathrm{ZnO}$ and its alloys are having vast device applications such as light emitting diodes (LEDs), solar cells, and optical waveguides [1-3]. ZnO is nontoxic, highly transparent along with high mechanical and thermal stability. Several researchers explore that the dopants can improve the electrical and optical properties of $\mathrm{ZnO}$ such as Al, In, and $\mathrm{Sn}$ [4-6]. When Sn was added into $\mathrm{ZnO}$ for doping, $\mathrm{Sn}^{+4}$ substitutes $\mathrm{Zn}^{+2}$ site in the $\mathrm{ZnO}$ crystal structure resulting in two more free electrons to contribute to the electric conduction [7]. The ionic radius of $\mathrm{Sn}^{+4}(0.069 \mathrm{~nm})$ is smaller than $\mathrm{Zn}^{+2}(0.074 \mathrm{~nm})$; therefore, $\mathrm{Sn}^{+4}$ ions can replace $\mathrm{Zn}^{+2}$ ions in substitution sites [8].

$\mathrm{ZnO}$ can be prepared by varieties of different techniques such as pulsed laser deposition (PLD) [9], RF sputtering [10], chemical vapor deposition (CVD) [11], sol-gel [12], metal organic chemical vapor deposition (MOCVD) [13], and molecular beam epitaxy (MBE) [14]. Among them, sol-gel is the mostly used technique for $\mathrm{ZnO}$ preparation; it is low cost, needs low temperature, and can be implemented for largescale preparation as compared to other techniques [15].
In the present study, Sn-doped $\mathrm{ZnO}$ nanorods were successfully synthesized using sol-gel method. We also investigated the effects of postannealing temperatures on structural, optical, electrical, and photoresponse properties. The results of this investigation contribute to the application of synthesized nanostructures in optical devices and heterojunction solar cells.

\section{Experimental}

$\mathrm{ZnO}$ seed solution was prepared by using low cost sol-gel spin coating method as reported in our previous research [16]. Briefly, 3.84 g zinc acetate dihydrate was dissolved in $50 \mathrm{~mL}$ 2-methoxyethanol and $1.069 \mathrm{~g}$ monoethanolamine. Monoethanolamine acts as a stabilizer and was added dropwise under stirring and constant temperature. Thus, a $\mathrm{ZnO}$ solution of concentration $0.35 \mathrm{M}$ was prepared. The solution was stirred for 2 hours at $60^{\circ} \mathrm{C}$ until a transparent and homogeneous solution was obtained. The prepared solution was stored overnight at room temperature. The aged solution was spin-coated on glass substrate using spin coater which was rotated at $3000 \mathrm{rpm}$ for $30 \mathrm{~s}$. The film was heated at $250^{\circ} \mathrm{C}$ 


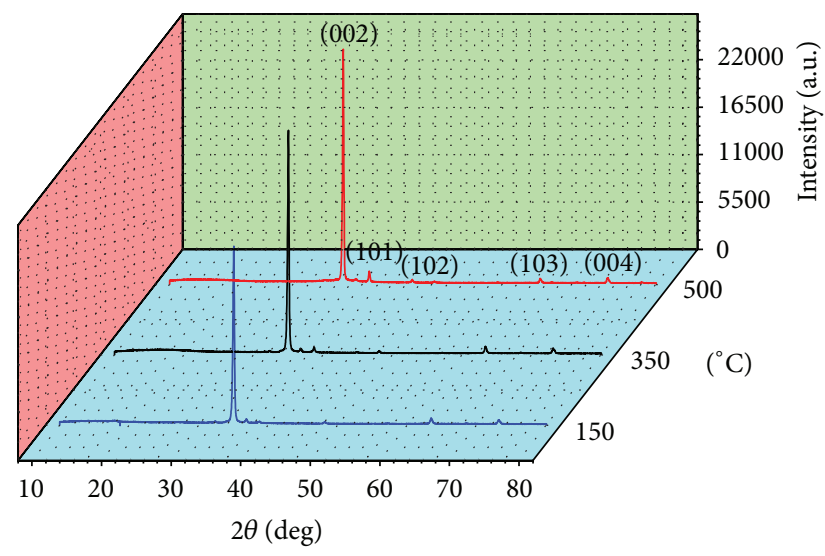

FIGURE 1: XRD pattern of $\mathrm{Sn}$-doped $\mathrm{ZnO}$ nanorods postannealed at different temperatures.

for $20 \mathrm{~min}$ after each coating. The coating-to-drying process was repeated for five times, and thus produced films were annealed at $500^{\circ} \mathrm{C}$ for 1 hour.

The $\mathrm{ZnO}$ nanorods were grown on seeded glass substrate using hydrothermal growth method. The growth solution was prepared by mixing zinc nitrate hexahydrate $(0.1 \mathrm{M})$, tin chloride dihydrate $(0.001 \mathrm{M})$ and hexamethyltetramine $(0.1 \mathrm{M})$ in $150 \mathrm{~mL}$ deionized water (DI). The solution was sonicated for $30 \mathrm{~min}$ at $50^{\circ} \mathrm{C}$ in an ultrasonicator (Delta $\mathrm{DC} 200 \mathrm{H})$. The seeded substrates were placed vertically so that the seeded side was facing down in the growth solution. The growth was done in a preheated oven at $93^{\circ} \mathrm{C}$ for 6 hours. After the growth, samples were washed with DI water to remove the residual salts and dried using $\mathrm{N}_{2}$ gun. The synthesized samples were postannealed at temperatures of 150,350 , and $500^{\circ} \mathrm{C}$ for 1 hour under ambient environment. Silver electrodes were deposited on the top of Sn-doped $\mathrm{ZnO}$ nanorods using hard mask. The metal was evaporated via Edwards Auto 306 thermal evaporation in a vacuum environment.

The surface morphology of Sn-doped $\mathrm{ZnO}$ nanorods was examined using scanning electron microscopy (SEM JEOL6460LA). The crystal structure and orientation of Sndoped $\mathrm{ZnO}$ nanorods were investigated using X-ray diffractometer (XRD, Bruker AXS D8 Advance). The UV-Visible (UV-Vis) spectra of $\mathrm{Sn}$-doped $\mathrm{ZnO}$ nanorods were obtained using a Lambda35 UV-Vis spectrometer (Perkin Elmer). A Keithley 2400 source meter was used to determine currentto-voltage $(I-V)$ and current-to-time $(I-t)$ characterization. Optical properties were determined by UV-Vis spectroscopy (HP 8453, Agilent). A digital lock-in amplifier (SR 830) and a 500 W Xenon lamp (SVX 1450) were used to characterize the spectral response. All of the measurements were performed in an ambient environment.

\section{Results and Discussion}

Figure 1 depicts the XRD pattern of $\mathrm{Sn}$-doped $\mathrm{ZnO}$ nanorods postannealed at temperatures of 150,350 , and $500^{\circ} \mathrm{C}$. The obtained spectra showed several peaks at (002), (101), (102),
(103), and (004) planes, which are consistent with previously reported values [17-21]. All the diffraction peaks are associated with the JCPDS card no. 036-1451 of the hexagonal $\mathrm{ZnO}$ structure.

No other peaks of impurities such as zinc nitrate hexahydrate and hexamethyltetramine were observed in the spectra. It was observed that all the postannealed Sn-doped $\mathrm{ZnO}$ nanorods have preferential growth at (002) orientation. The intensity of peak appeared at (002) plane found increased with an increase in postannealing temperature. The intensification of peak that appeared at (002) plane indicates that crystal quality of the synthesized $\mathrm{Sn}$-doped $\mathrm{ZnO}$ nanorods gets improved with the increase in postannealing temperature. The average crystalline size was calculated using Scherrer's formula [22-24]:

$$
D=\frac{0.9 \lambda}{B \cos \theta}
$$

where $D$ is the crystalline size, $\lambda$ is the wavelength of X-ray, $\theta$ is the angle of diffraction, and $B$ is the FWHM of the observed peak. The calculated crystallite size values were 30,32 , and $36.9 \mathrm{~nm}$ with respect to postannealing temperatures of 150 , 350 , and $500^{\circ} \mathrm{C}$, respectively, which revealed that crystallite size increased as the postannealing temperature increased. The increment in crystalline size may be attributed to particles merging activity at high postannealing temperature [25].

Figure 2 illustrates the SEM images of Sn-doped $\mathrm{ZnO}$ nanorods postannealed at temperatures of 150, 350, and $500^{\circ} \mathrm{C}$, respectively. It was notified that all the substrates were densely covered with vertically aligned nanorods. As the postannealing temperature increased from 150 to $500^{\circ} \mathrm{C}$, the $\mathrm{Sn}$-doped $\mathrm{ZnO}$ nanorods showed noticeable variations on the surface morphology as shown in Figures 2(b) and 2(c). Based on dynamics growth and thermodynamics process, particles likely move more disorderly at maximum postannealing temperature than at other temperatures; as a result, the anisotropic growth of crystals is perturbed because of the surrounding driving force; hence, $\mathrm{Sn}$-doped $\mathrm{ZnO}$ nanorods show a granular shape (Figures 2(b) and 2(c)) [26]. Furthermore, Sn-doped $\mathrm{ZnO}$ nanorods at a higher postannealing temperature are more agglomerated and spherical than those at a lower postannealing temperature; this result indicates that the samples are highly crystalline in nature [27].

The inset of Figure 3 shows the absorbance spectra, which displayed that as the postannealing temperature increases, the absorbance edge shifts towards the lower wavelength, indicating expansion in the optical bandgap. The optical bandgap of direct-transition semiconductor $\mathrm{Sn}$-doped $\mathrm{ZnO}$ nanorods was calculated using Tauc model [28] and compared with the reported values $[19,20]$ :

$$
\alpha h v=A\left(h v-E_{g}\right) \frac{1}{2},
$$

where $\alpha$ is the absorbance coefficient, $h v$ is the photon energy, $A$ is an energy independent constant, and $E_{g}$ is the energy gap. The optical bandgap of $\mathrm{Sn}$-doped $\mathrm{ZnO}$ nanorods which 

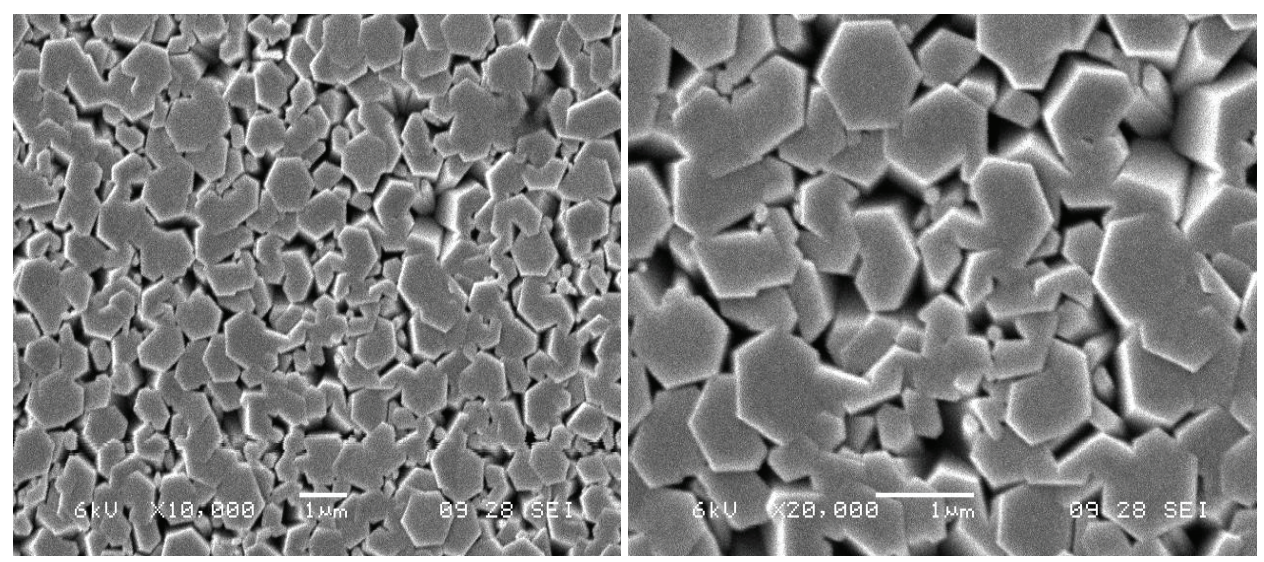

(a)
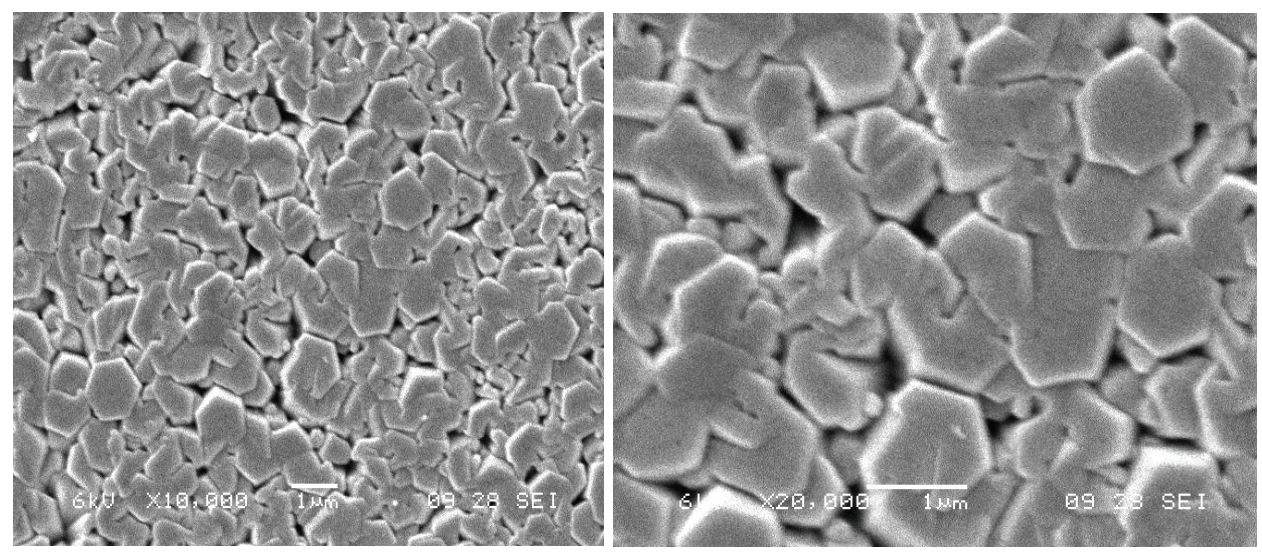

(b)
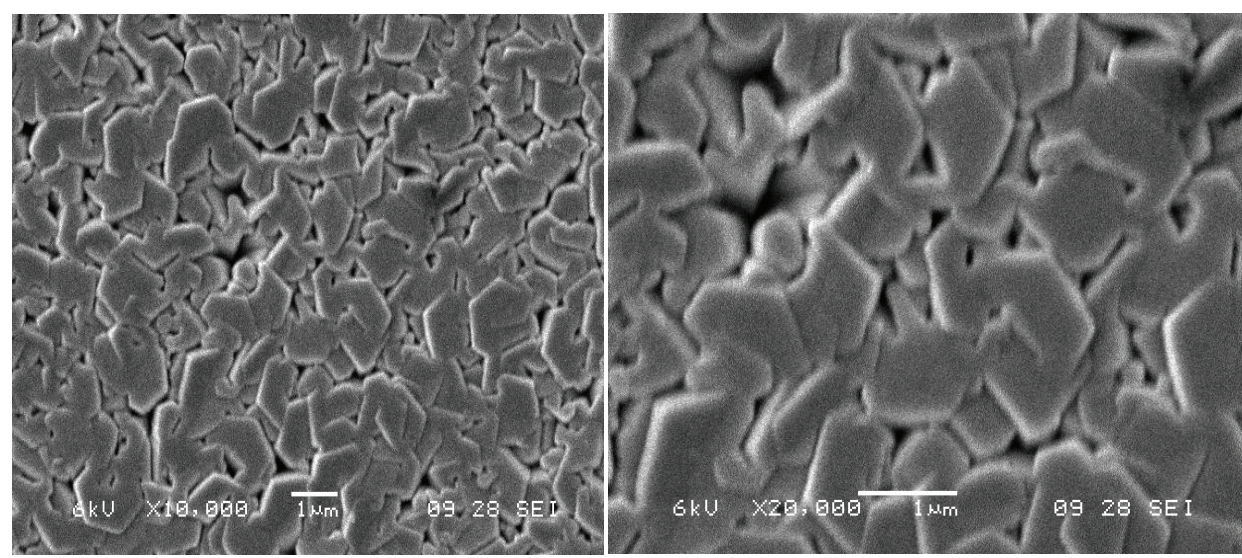

(c)

FIGURE 2: SEM images of Sn-doped $\mathrm{ZnO}$ nanorods at different postannealing temperatures (a) $150^{\circ} \mathrm{C}$, (b) $300^{\circ} \mathrm{C}$, and (c) $500^{\circ} \mathrm{C}$.

were postannealed at temperatures of 150,350 , and $500^{\circ} \mathrm{C}$ was determined by extrapolating the straight section of the plot of $(\alpha h v)^{2}$ versus photon energy as shown in Figure 3.

The calculated values of the optical bandgap energy were $3.18 \mathrm{eV}, 3.21 \mathrm{eV}$, and $3.33 \mathrm{eV}$ for the samples postannealed at temperatures of 150,350 , and $500^{\circ} \mathrm{C}$, respectively. The change in bandgap energy may be attributed to the electron-electron and electron impurity scattering $[29,30]$.
Our knowledge of refractive index $n$ is important in the advancement of different materials in optoelectronic research. Therefore, $n$ as a function of wavelength is an important parameter and should be evaluated for the design of various devices, such as integrated optical switches, filters, and modulators. Efforts have been devoted to relate $n$ to energy gap $\left(E_{g}\right)$ based on simple relationships [31-35]. In the present study, various relationships between $n$ and $E_{g}$ were 
TABLE 1: Energy gaps $\left(E_{g}\right)$, calculated refractive indices $(n)$ and optical dielectric constant $\varepsilon_{\infty}$ of nanostructure Sn-ZnO using Ravindra et al. [35] Hervé and Vandamme [36], and Ghosh et al. [37] models.

\begin{tabular}{lccc}
\hline $\begin{array}{l}\text { Annealing } \\
\text { temperatures }\left({ }^{\circ} \mathrm{C}\right)\end{array}$ & Band gap energy $(\mathrm{eV})$ & Refractive index $(n)$ & $\begin{array}{c}\text { Optical dielectric constant } \\
\left(\varepsilon_{\infty}\right)\end{array}$ \\
\hline 150 & $3.18,3.44^{\mathrm{a}}, 1.57^{\mathrm{b}}, 0.73^{\mathrm{c}}, 0.88^{\mathrm{d}}, 2.26^{\mathrm{e}}$ & $2.0764^{\mathrm{f}}, 2.2960^{\mathrm{g}}, 2.3335^{\mathrm{h}}, 2.008^{\mathrm{i}}$ & $4.3114^{\mathrm{f}}, 5.2716^{\mathrm{g}}, 5.4452^{\mathrm{h}}$ \\
350 & 3.21 & $2.0578^{\mathrm{f}}, 2.2876^{\mathrm{g}}, 2.3274^{\mathrm{h}}$ & $4.2345^{\mathrm{f}}, 5.2331^{\mathrm{g}}, 5.4167^{\mathrm{h}}$ \\
500 & 3.33 & $1.9834^{\mathrm{f}}, 2.2546^{\mathrm{g}}, 2.3037^{\mathrm{h}}$ & $3.9338^{\mathrm{f}}, 5.0832^{\mathrm{g}}, 5.3070^{\mathrm{h}}$ \\
\hline
\end{tabular}

${ }^{\mathrm{a}}$ Huemmer [39]-Exp.

${ }^{\mathrm{b}}$ Charifi et al. [41]-Theor.

${ }^{\mathrm{c}}$ Schleife et al. [42] - Theor.

${ }^{\mathrm{d}} \mathrm{Xu}$ and Ching [43]-Theor.

S'Schröer et al. [44]-Theor.

${ }^{\mathrm{f}}$ Ravindra et al. [35].

${ }^{8}$ Hervé and Vandamme [36].

${ }^{\mathrm{h}}$ Ghosh et al. [37].

'Weast [40]-Exp.

reviewed. Ravindra et al. [35] suggested that different relationships are present between bandgap and high-frequency $n$, in which a linear form of $n$ as a function of $E_{g}$ is presented as follows:

$$
n=\alpha+\beta E_{g}
$$

where $\alpha=4.048$ and $\beta=-0.62 \mathrm{eV}^{-1}$. Light refraction and dispersion are also considered. Hervé and Vandamme [36] proposed an empirical relationship as follows:

$$
n=\sqrt{1+\left(\frac{A}{E_{g}+B}\right)^{2}}
$$

where $A=13.6 \mathrm{eV}$ and $B=3.4 \mathrm{eV}$. Ghosh et al. [37] showed an empirical relationship for groups II to VI semiconductors on the basis of the band structure and quantum dielectric considerations of Penn [38] and Van Vechten:

$$
n^{2}-1=\frac{A}{\left(E_{g}+B\right)^{2}},
$$

where $A=25 E_{g}+212, B=0.21 E_{g}+4.25$, and $\left(E_{g}+B\right)$ refer to an appropriate average optical energy gap of the material. The calculated $n$ of the end-point compounds and $E_{g}$ (Table 1) are consistent with experimental $[39,40]$ and theoretical $[41-$ $44]$ values. These results are verified by calculating the optical dielectric constant $\varepsilon_{\infty}$, which is dependent on $n$; hence, $\varepsilon_{\infty}=$ $n^{2}$ [45]. The $n$ obtained using the Hervé and Vandamme model [36] is important to enhance the detecting and sensing of $\mathrm{ZnO}$ nanostructure. Therefore, high absorption may be attributed to an increase in sensor efficiency.

Current-to-voltage characteristic was carried out to study the postannealing effect on the electrical properties of Sndoped $\mathrm{ZnO}$ nanorods. The effect of postannealing temperature can be visually inspected in current-voltage characteristic curves of Figure 4.

The linear relationship between current-to-voltage curves demonstrates the ohmic nature of $\mathrm{Sn}$-doped $\mathrm{ZnO}$ nanorods.
The resistivity $\rho$ at postannealing temperatures of 150,350 , and $500^{\circ} \mathrm{C}$ can be calculated from the $I-V$ curves by using the following relation:

$$
\rho=R\left(\frac{A}{l}\right)
$$

where $R$ is the resistance, $A$ is the area of electrodes, and $l$ is the length of nanorods. Resistivity values of $\mathrm{Sn}$-doped $\mathrm{ZnO}$ nanorods annealed at temperatures of 150,350 , and $500^{\circ} \mathrm{C}$ were $\left(316.75 \times 10^{6}\right),\left(55.89 \times 10^{6}\right)$, and $\left(20.95 \times 10^{6}\right) \Omega-\mathrm{cm}$, respectively. It can be revealed that the decrement in electrical conductivity was a causative factor due to reduced grainboundary scattering and an increase in electron mobility with grain size growth [46].

Our X-ray diffraction result is consistent with those in previous studies [47-51], in which crystallinity is improved with respect to annealing temperature. Photoresponse $\left(I_{\text {on }} /\right.$ $\left.I_{\text {off }}\right)$ increases as annealing temperature increases [52-58]. In $\mathrm{ZnO}$-type materials, photoresponse is generally caused by oxygen desorption and adsorption process originating from either a bulk- or surface-related process $[52,59,60]$.

Figures 5(a) and 5(b) show the responsivity and photoresponse curves of the $\mathrm{Sn}$-doped $\mathrm{ZnO}$ nanorods postannealed at 150,350 , and $500^{\circ} \mathrm{C}$. In this study, the sharp cutoff in the responsivity curves decreased in magnitude at approximately $370 \mathrm{~nm}$. The maximum responsivity of our sensor at an applied bias of $5 \mathrm{~V}$ was $1.7 \mathrm{~A} / \mathrm{W}$, which is higher than previously reported values $[61,62]$. The photoresponse spectra also showed that UV light response occurs faster at higher postannealing temperature than at other temperatures. This phenomenon may occur possibly because crystallinity is improved, defect ratio decreases, and barrier height increases at maximum postannealing temperatures [55]. This improved crystallinity also creates a well-interconnected network [53] of Sn-doped $\mathrm{ZnO}$ nanorods, thereby enhancing the electronic flow along the nanorod/nanowire 


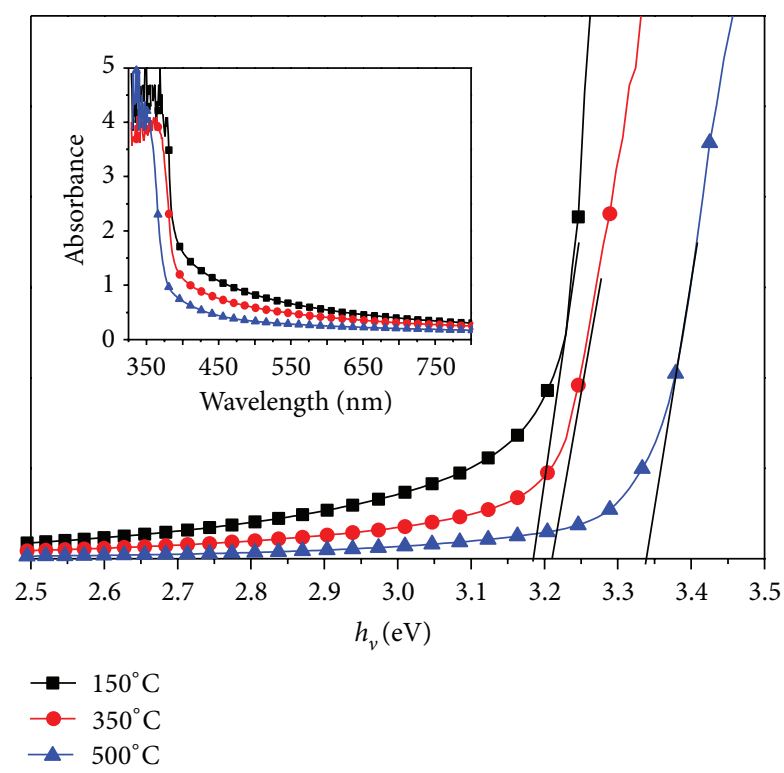

Figure 3: A plot of $(\alpha h v)^{2}$ versus photon energy for Sn-doped $\mathrm{ZnO}$ nanorods at different postannealing temperatures.

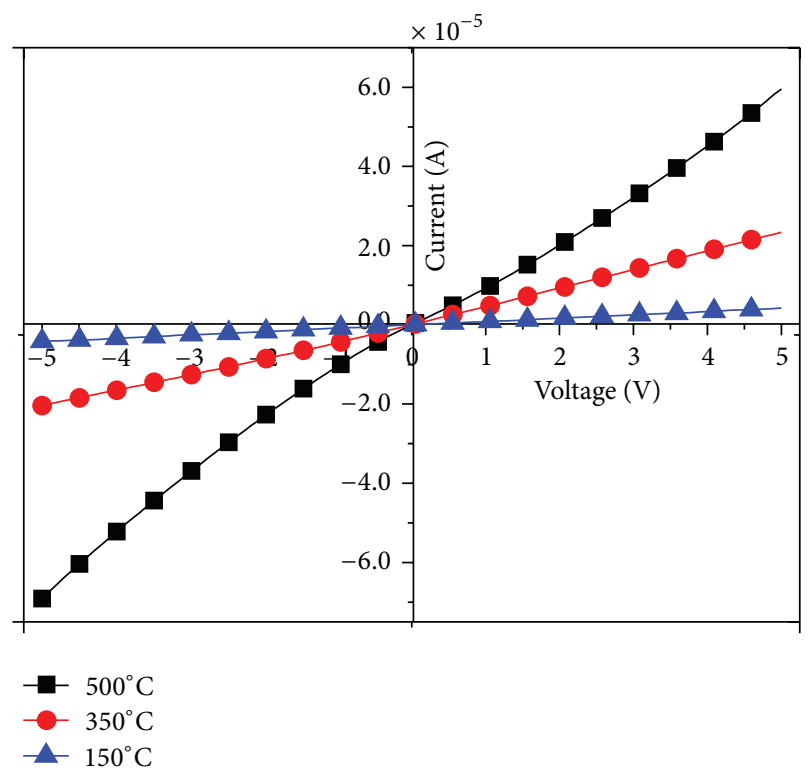

Figure 4: $I-V$ curves of Sn-doped $\mathrm{ZnO}$ nanorods postannealed at different temperatures.

axis $[63,64]$. However, electrons experience resistance along the nanorod axis at low annealing temperatures; as a result, photoresponse is decreased.

\section{Conclusion}

$\mathrm{Sn}$-doped $\mathrm{ZnO}$ nanorods were successfully synthesized on glass substrate by low temperature sol-gel method. The effect of postannealing temperature on the structural, optical, electrical, and photoresponse properties of Sn-doped $\mathrm{ZnO}$ nanorods is investigated using $\mathrm{X}$-ray diffraction, UVVis spectroscopy, $I-V$, and $I-t$ measurements, respectively. The crystallinity and $c$-axis orientation of the Sn-doped

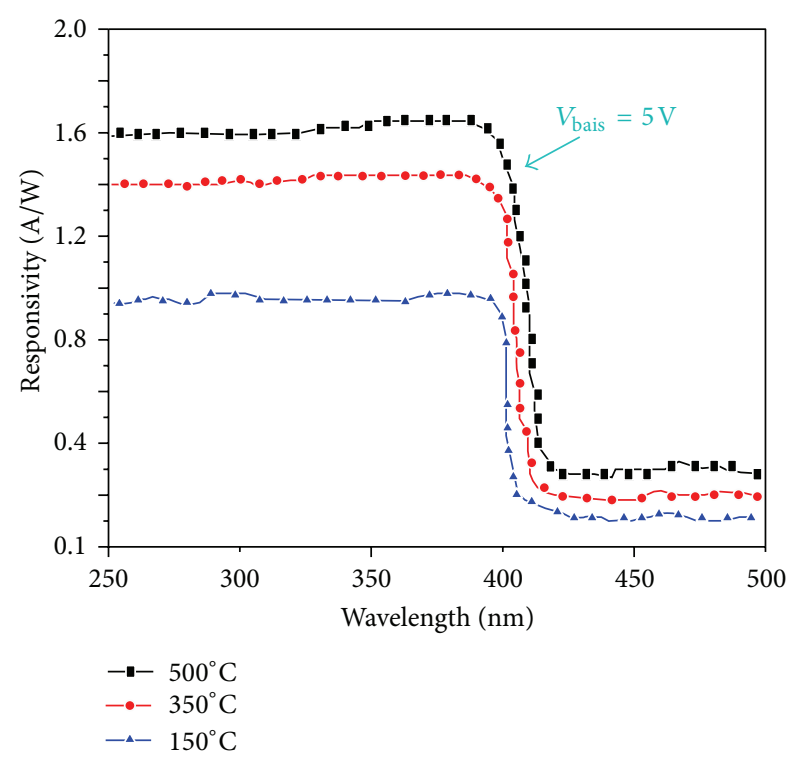

(a)

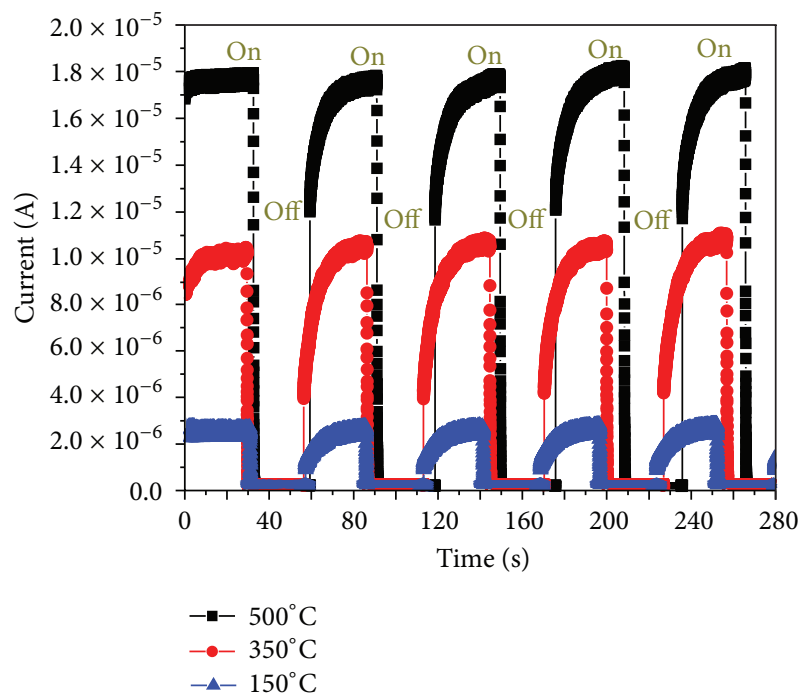

(b)

FIgURE 5: (a) The spectral responsivity and (b) current-to-time photoresponse curves of $\mathrm{Sn}$-doped $\mathrm{ZnO}$ nanorods at different postannealing temperatures.

$\mathrm{ZnO}$ nanorods were increased with annealing temperatures. The optical bandgap energy of Sn-doped $\mathrm{ZnO}$ nanorods decreased as the annealing temperature increases. Electrical characteristics reveal the effect of annealing temperature on the resistivity and photoresponse of $\mathrm{Sn}$-doped $\mathrm{ZnO}$ nanorods. Hence, the proposed Hervé and Vandamme model and the improved photoresponse of postannealed samples are applicable in optoelectronic devices.

\section{Acknowledgments}

The authors acknowledge the financial support from the Ministry of higher education (MOHE). The authors would 
also like to thank the technical staff of Institute of Nano ElectronicEngineering and School of Microelectronic Engineering, Universiti Malaysia Perlis for their kind support to smoothly perform the research.

\section{References}

[1] D. C. Kim, W. S. Han, B. H. Kong, H. K. Cho, and C. H. Hong, "Fabrication of the hybrid ZnO LED structure grown on p-type GaN by metal organic chemical vapor deposition," Physica $B$, vol. 401-402, pp. 386-390, 2007.

[2] C. T. Chen, F. C. Hsu, Y. M. Sung et al., "Effects of metalfree conjugated oligomer as a surface modifier in hybrid polymer/ZnO solar cells," Solar Energy Materials and Solar Cells, vol. 107, pp. 69-74, 2012.

[3] T. Shiosaki, M. Adachi, and A. Kawabata, "Sputtering and chemical vapour deposition of piezoelectric $\mathrm{ZnO}$, AlN and K3Li2Nb5O15 films for optical waveguides and surface acoustic wave devices," Thin Solid Films, vol. 96, no. 2, pp. 129-140, 1982.

[4] S. W. Xue, X. T. Zu, W. G. Zheng, M. Y. Chen, and X. Xiang, "Effects of annealing and dopant concentration on the optical characteristics of $\mathrm{ZnO}: \mathrm{Al}$ thin films by sol-gel technique," Physica B, vol. 382, no. 1-2, pp. 201-204, 2006.

[5] C. E. Benouis, M. Benhaliliba, A. Sanchez Juarez, M. S. Aida, F. Chami, and F. Yakuphanoglu, "The effect of indium doping on structural, electrical conductivity, photoconductivity and density of states properties of $\mathrm{ZnO}$ films," Journal of Alloys and Compounds, vol. 490, no. 1-2, pp. 62-67, 2010.

[6] M. Kashif, U. Hashim, S. M. Usman Ali, M. Willander, and M. Ibrar-Ul-Haque, "Structure and optical characterization of $\mathrm{ZnO}-\mathrm{Sn}$ thin films," in Proceedings of the 14th IEEE International Multitopic Conference 2011 (INMIC '11), pp. 188-190, December 2011.

[7] M. Tsega and D. H. Kuo, "The performance of the donor and acceptor doping in the $\mathrm{Cu}$-rich $\mathrm{Cu} 2 \mathrm{ZnSnSe} 4$ bulks with different $\mathrm{Zn} / \mathrm{Sn}$ ratios," Solid State Communications, vol. 164, pp. 42-46, 2013.

[8] J.-H. Lee and B.-O. Park, "Transparent conducting ZnO:Al, In and $\mathrm{Sn}$ thin films deposited by the sol-gel method," Thin Solid Films, vol. 426, no. 1-2, pp. 94-99, 2003.

[9] B. L. Zhu, X. Z. Zhao, F. H. Su et al., "Low temperature annealing effects on the structure and optical properties of $\mathrm{ZnO}$ films grown by pulsed laser deposition," Vacuum, vol. 84, no. 11, pp. 1280-1286, 2010.

[10] N. Tang, J. Wang, H. Xu, H. Peng, and C. Fan, "Optical characterization of $\mathrm{ZnO}$ thin films deposited by RF magnetron sputtering method," Science in China E, vol. 52, no. 8, pp. 22002203, 2009.

[11] M. Purica, E. Budianu, E. Rusu, M. Danila, and R. Gavrila, "Optical and structural investigation of $\mathrm{ZnO}$ thin films prepared by chemical vapor deposition (CVD)," Thin Solid Films, vol. 403-404, pp. 485-488, 2002.

[12] L. Cui, G. G. Wang, H. Y. Zhang, R. Sun, X. P. Kuang, and J. C. Han, "Effect of film thickness and annealing temperature on the structural and optical properties of $\mathrm{ZnO}$ thin films deposited on sapphire (0001) substrates by sol-gel," Ceramics International, vol. 39, no. 3, pp. 3261-3268, 2013.

[13] A. M. Torres-Huerta, M. A. Domínguez-Crespo, S. B. BrachettiSibaja, J. Arenas-Alatorre, and A. Rodríguez-Pulido, "Effect of the substrate on the properties of $\mathrm{ZnO}-\mathrm{MgO}$ thin films grown by atmospheric pressure metal-organic chemical vapor deposition," Thin Solid Films, vol. 519, no. 18, pp. 6044-6052, 2011.

[14] X. Pan, P. Ding, H. He et al., "Optical properties and structural characteristics of $\mathrm{ZnO}$ thin films grown on a-plane sapphire substrates by plasma-assisted molecular beam epitaxy," Optics Communications, vol. 285, no. 21-22, pp. 4431-4434, 2012.

[15] P. Sagar, M. Kumar, and R. M. Mehra, "Electrical and optical properties of sol-gel derived $\mathrm{ZnO}$ : Al thin films," Materials Science, vol. 52, no. 3, pp. 686-696, 2005.

[16] M. Kashif, S. M. Usman Ali, M. E. Ali et al., "Morphological, optical, and Raman characteristics of $\mathrm{ZnO}$ nanoflakes prepared via a sol-gel method," Physica Status Solidi A, vol. 209, no. 1, pp. 143-147, 2012.

[17] C. Wu, L. Shen, H. Yu, Q. Huang, and Y. C. Zhang, "Synthesis of $\mathrm{Sn}$-doped $\mathrm{ZnO}$ nanorods and their photocatalytic properties," Materials Research Bulletin, vol. 46, no. 7, pp. 1107-1112, 2011.

[18] X.-S. Fang, C.-H. Ye, L.-D. Zhang, Y. Li, and Z.-D. Xiao, "Formation and optical properties of thin and wide tin-doped ZnO nanobelts," Chemistry Letters, vol. 34, no. 3, pp. 436-437, 2005.

[19] R. Mariappan, V. Ponnuswamy, and P. Suresh, "Effect of doping concentration on the structural and optical properties of pure and tin doped zinc oxide thin films by nebulizer spray pyrolysis (NSP) technique," Superlattices and Microstructures, vol. 52, no. 3, pp. 500-513, 2012.

[20] J.-H. Sun, S.-Y. Dong, J.-L. Feng, X.-J. Yin, and X.-C. Zhao, "Enhanced sunlight photocatalytic performance of Sn-doped $\mathrm{ZnO}$ for Methylene Blue degradation," Journal of Molecular Catalysis A, vol. 335, no. 1-2, pp. 145-150, 2011.

[21] R. Viswanatha, Y. Arthoba Nayak, T. G. Venkatesha, and C. C. Vidyasagar, "Synthesis, characterization and optical properties of Sn-ZnO nanoparticle," Nanoscience and Nanotechnology, vol. 3, no. 1, pp. 16-20, 2013.

[22] M. Kashif, U. Hashim, M. E. Ali, K. L. Foo, and S. M. Usman Ali, "Morphological, structural, and electrical characterization of sol-gel-synthesized ZnO nanorods," Journal of Nanomaterials, vol. 2013, Article ID 478942, 7 pages, 2013.

[23] Q. Humayun, M. Kashif, and U. Hashim, "Area-selective $\mathrm{ZnO}$ thin film deposition on variable microgap electrodes and their impact on UV sensing," Journal of Nanomaterials, vol. 2013, Article ID 301674, 5 pages, 2013.

[24] Q. Humayun, M. Kashif, and U. Hashim, "ZnO thin film deposition on butterfly shaped electrodes for ultraviolet sensing applications," Optik, vol. 124, no. 23, pp. 5961-5963, 2013.

[25] M. H. Mamat, M. Z. Sahdan, Z. Khusaimi, and M. Rusop, "Electrical characteristics of sol-gel derived aluminum doped zinc oxide thin films at different annealing temperatures," in Proceedings of the International Conference on Electronic Devices, Systems and Applications (ICEDSA '10), pp. 408-411, April 2010.

[26] J. Yang, M. Gao, Y. Zhang et al., "Effects of annealing temperature on morphologies and optical properties of $\mathrm{ZnO}$ nanostructures," Superlattices and Microstructures, vol. 44, no. 2, pp. 137-142, 2008.

[27] Pandiyarajan and B. Karthikeyan, "Optical properties of annealing induced post growth $\mathrm{ZnO}$ : $\mathrm{ZnFe} 2 \mathrm{O} 4$ nanocomposites," Spectrochimica Acta A, vol. 106, pp. 247-252, 2013.

[28] D. S. Dhawale, A. M. More, S. S. Latthe, K. Y. Rajpure, and C. D. Lokhande, "Room temperature synthesis and characterization of CdO nanowires by chemical bath deposition (CBD) method," Applied Surface Science, vol. 254, no. 11, pp. 3269-3273, 2008. 
[29] H. Zeng, G. Duan, Y. Li, S. Yang, X. Xu, and W. Cai, "Blue luminescence of $\mathrm{ZnO}$ nanoparticles based on non-equilibrium processes: defect origins and emission controls," Advanced Functional Materials, vol. 20, no. 4, pp. 561-572, 2010.

[30] B. E. Sernelius, K.-F. Berggren, Z.-C. Jin, I. Hamberg, and C. G. Granqvist, "Band-gap tailoring of $\mathrm{ZnO}$ by means of heavy Al doping," Physical Review B, vol. 37, no. 17, pp. 10244-10248, 1988.

[31] T. S. Moss, "A relationship between the refractive index and the infra-red threshold of sensitivity for photoconductors," Proceedings to the Physical Society B, vol. 63, no. 3, article 302, pp. 167-176, 1950.

[32] V. P. Gupta and N. M. Ravindra, "Comments on the moss formula," Physica Status Solidi B, vol. 100, no. 2, pp. 715-719, 1980.

[33] P. Hervé and L. K. J. Vandamme, "General relation between refractive index and energy gap in semiconductors," Infrared Physics and Technology, vol. 35, no. 4, pp. 609-615, 1994.

[34] H. J. Fan, R. Scholz, F. M. Kolb et al., "On the growth mechanism and optical properties of $\mathrm{ZnO}$ multi-layer nanosheets," Applied Physics A, vol. 79, no. 8, pp. 1895-1900, 2004.

[35] N. M. Ravindra, S. Auluck, and V. K. Srivastava, "On the penn gap in semiconductors," Physica Status Solidi B, vol. 93, no. 2, pp. K155-K160, 1979.

[36] P. J. L. Hervé and L. K. J. Vandamme, "Empirical temperature dependence of the refractive index of semiconductors," Journal of Applied Physics, vol. 77, no. 10, pp. 5476-5477, 1995.

[37] D. K. Ghosh, L. K. Samanta, and G. C. Bhar, "A simple model for evaluation of refractive indices of some binary and ternary mixed crystals," Infrared Physics, vol. 24, no. 1, pp. 43-47, 1984.

[38] D. R. Penn, "Wave-number-dependent dielectric function of semiconductors," Physical Review, vol. 128, no. 5, pp. 2093-2097, 1962.

[39] K. Huemmer, "Interband magnetoreflection of ZnO," Physica Status Solidi B, vol. 56, no. 1, pp. 249-260, 1973.

[40] R. C. Weast, Handbook of Chemistry \& Physics, CRC Press, 5th edition, 1973.

[41] Z. Charifi, H. Baaziz, and A. H. Reshak, "Ab-initio investigation of structural, electronic and optical properties for three phases of ZnO compound," Physica Status Solidi B, vol. 244, no. 9, pp. 3154-3167, 2007.

[42] A. Schleife, F. Fuchs, J. Furthmüller, and F. Bechstedt, "Firstprinciples study of ground- and excited-state properties of $\mathrm{MgO}, \mathrm{ZnO}$, and CdO polymorphs," Physical Review B, vol. 73, no. 24, Article ID 245212, 2006.

[43] Y.-N. Xu and W. Y. Ching, "Electronic, optical, and structural properties of some wurtzite crystals," Physical Review B, vol. 48, no. 7, pp. 4335-4351, 1993.

[44] P. Schröer, P. Krüger, and J. Pollmann, "First-principles calculation of the electronic structure of the wurtzite semiconductors ZnO and ZnS," Physical Review B, vol. 47, no. 12, pp. 6971-6980, 1993.

[45] G. A. Samara, "Temperature and pressure dependences of the dielectric constants of semiconductors," Physical Review B, vol. 27, no. 6, pp. 3494-3505, 1983.

[46] O. Vigil, F. Cruz, A. Morales-Acevedo, G. Contreras-Puente, L. Vaillant, and G. Santana, "Structural and optical properties of annealed CdO thin films prepared by spray pyrolysis," Materials Chemistry and Physics, vol. 68, no. 1-3, pp. 249-252, 2001.

[47] B. L. Zhu, X. Z. Zhao, F. H. Su et al., "Low temperature annealing effects on the structure and optical properties of $\mathrm{ZnO}$ films grown by pulsed laser deposition," Vacuum, vol. 84, no. 11, pp. 1280-1286, 2010.

[48] S. W. Xue, X. T. Zu, W. G. Zheng, M. Y. Chen, and X. Xiang, "Effects of annealing and dopant concentration on the optical characteristics of $\mathrm{ZnO}: \mathrm{Al}$ thin films by sol-gel technique," Physica B, vol. 382, no. 1-2, pp. 201-204, 2006.

[49] G. P. Daniel, V. B. Justinvictor, P. B. Nair, K. Joy, P. Koshy, and P. V. Thomas, "Effect of annealing temperature on the structural and optical properties of $\mathrm{ZnO}$ thin films prepared by RF magnetron sputtering," Physica B, vol. 405, no. 7, pp. 17821786, 2010.

[50] R. Lotfi Orimi, "Investigation of the effect of annealing on the photoluminescence properties of $\mathrm{ZnO}$ nanoparticles, synthesized at low temperature," Optical Materials, vol. 35, no. 3, pp. 657-660, 2013.

[51] T. M. Hammad, J. K. Salem, and R. G. Harrison, "The influence of annealing temperature on the structure, morphologies and optical properties of $\mathrm{ZnO}$ nanoparticles," Superlattices and Microstructures, vol. 47, no. 2, pp. 335-340, 2010.

[52] R. Menon, A. Chowdhuri, M. Tomar, K. Sreenivas, and V. Gupta, "Enhanced photo-response of thermally treated Zinc oxide Ultra-violet photon detector with furnace method and pulsed laser irradiation," in Proceedings of the IEEE Sensors Conference, pp. 437-440, October 2009.

[53] K.-P. Kim, D. Chang, S. K. Lim, S.-K. Lee, H.-K. Lyu, and D.K. Hwang, "Thermal annealing effects on the dynamic photoresponse properties of $\mathrm{Al}$-doped $\mathrm{ZnO}$ nanowires network," Current Applied Physics, vol. 11, no. 6, pp. 1311-1314, 2011.

[54] H. Zhou, G.-J. Fang, N. Liu, and X.-Z. Zhao, "Effects of thermal annealing on the performance of $\mathrm{Al} / \mathrm{ZnO}$ nanorods $/ \mathrm{Pt}$ structure ultraviolet photodetector," Materials Science and Engineering $B$, vol. 176, no. 9, pp. 740-744, 2011.

[55] Y. Z. Li, X. M. Li, and X. D. Gao, "Effects of post-annealing on Schottky contacts of Pt/ZnO films toward UV photodetector," Journal of Alloys and Compounds, vol. 509, no. 26, pp. 7193-7197, 2011.

[56] F. . Yi, Y. Huang, Z. Zhang, Q. Zhang, and Y. Zhang, "Photoluminescence and highly selective photoresponse of $\mathrm{ZnO}$ nanorod arrays," Optical Materials, vol. 35, no. 8, pp. 1532-1537, 2013.

[57] S. Dhara and P. K. Giri, "Enhanced UV photosensitivity from rapid thermal annealed vertically aligned $\mathrm{ZnO}$ nanowires," Nanoscale Research Letters, vol. 6, article 504, no. 1, pp. 1-8, 2011.

[58] N. Baydogan, O. Karacasu, and H. Cimenoglu, "Effect of annealing temperature on $\mathrm{ZnO}: \mathrm{Al} / \mathrm{p}$-Si heterojunctions," Thin Solid Films, vol. 520, no. 17, pp. 5790-5796, 2012.

[59] M. H. Mamat, M. I. Che Khalin, N. N. H. Nik Mohammad et al., "Effects of annealing environments on the solutiongrown, aligned aluminium-doped zinc oxide nanorod-arraybased ultraviolet photoconductive sensor," Journal of Nanomaterials, vol. 2012, Article ID 189279, 15 pages, 2012.

[60] M. H. Mamat, Z. Khusaimi, M. Z. Musa, M. F. Malek, and M. Rusop, "Fabrication of ultraviolet photoconductive sensor using a novel aluminium-doped zinc oxide nanorod-nanoflake network thin film prepared via ultrasonic-assisted sol-gel and immersion methods," Sensors and Actuators A, vol. 171, no. 2, pp. 241-247, 2011.

[61] L. Luo, Y. Zhang, S. S. Mao, and L. Lin, "Fabrication and characterization of ZnO nanowires based UV photodiodes," Sensors and Actuators A, vol. 127, no. 2, pp. 201-206, 2006. 
[62] L. Guo, H. Zhang, D. Zhao et al., "High responsivity $\mathrm{ZnO}$ nanowires based UV detector fabricated by the dielectrophoresis method," Sensors and Actuators B, vol. 166-167, pp. 12-16, 2012.

[63] Q. Ahsanulhaq, J. H. Kim, J. S. Lee, and Y. B. Hahn, "Electrical and gas sensing properties of $\mathrm{ZnO}$ nanorod arrays directly grown on a four-probe electrode system," Electrochemistry Communications, vol. 12, no. 3, pp. 475-478, 2010.

[64] Q. Ahsanulhaq, J.-H. Kim, and Y.-B. Hahn, "Controlled selective growth of $\mathrm{ZnO}$ nanorod arrays and their field emission properties," Nanotechnology, vol. 18, no. 48, Article ID 485307, 2007. 

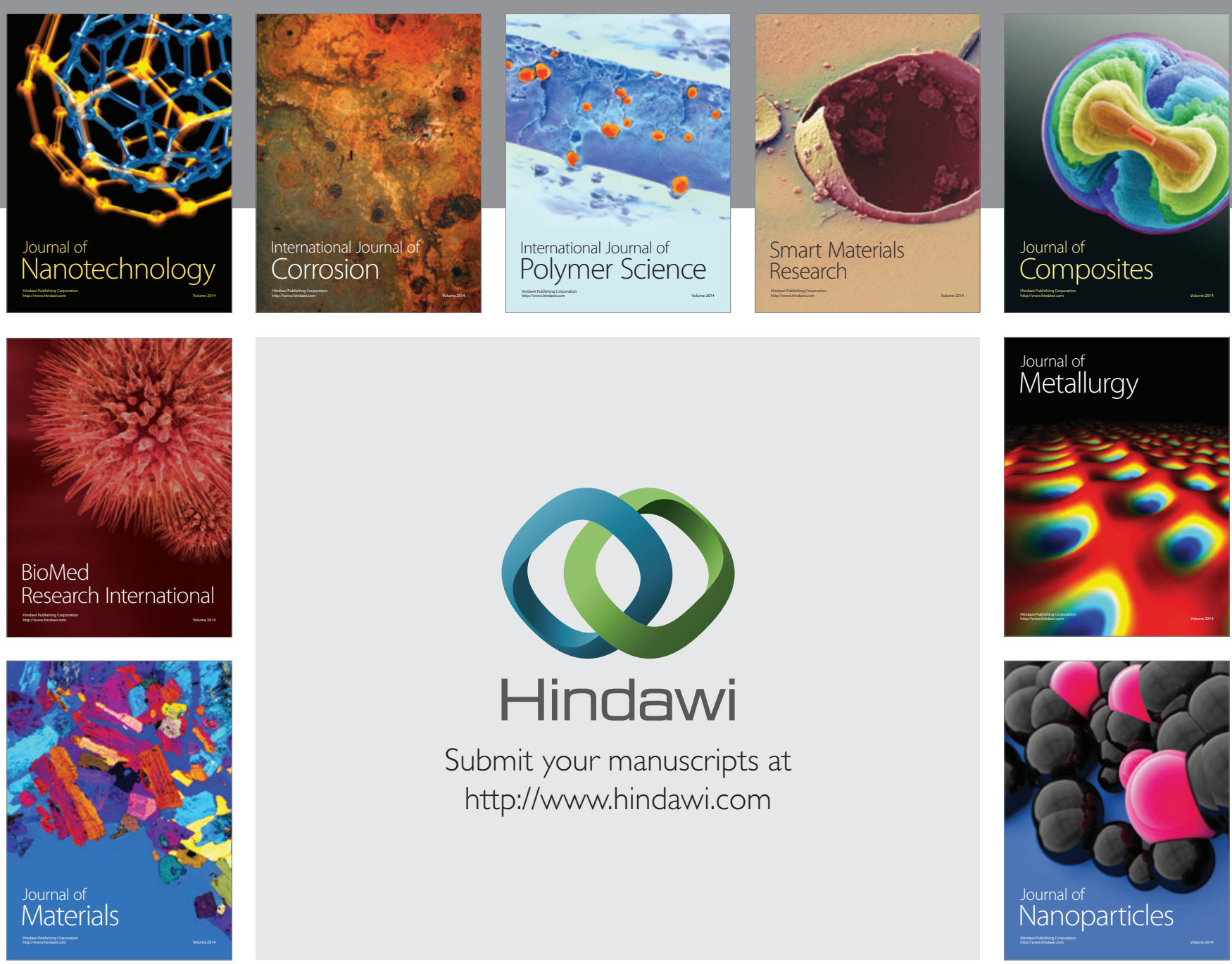

Submit your manuscripts at http://www.hindawi.com
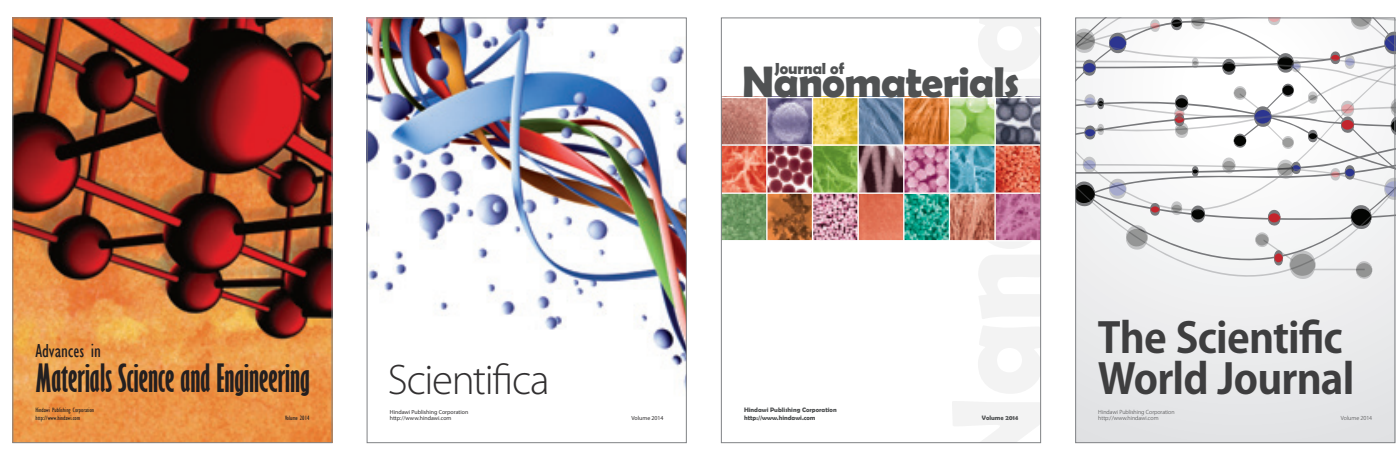

\section{The Scientific World Journal}
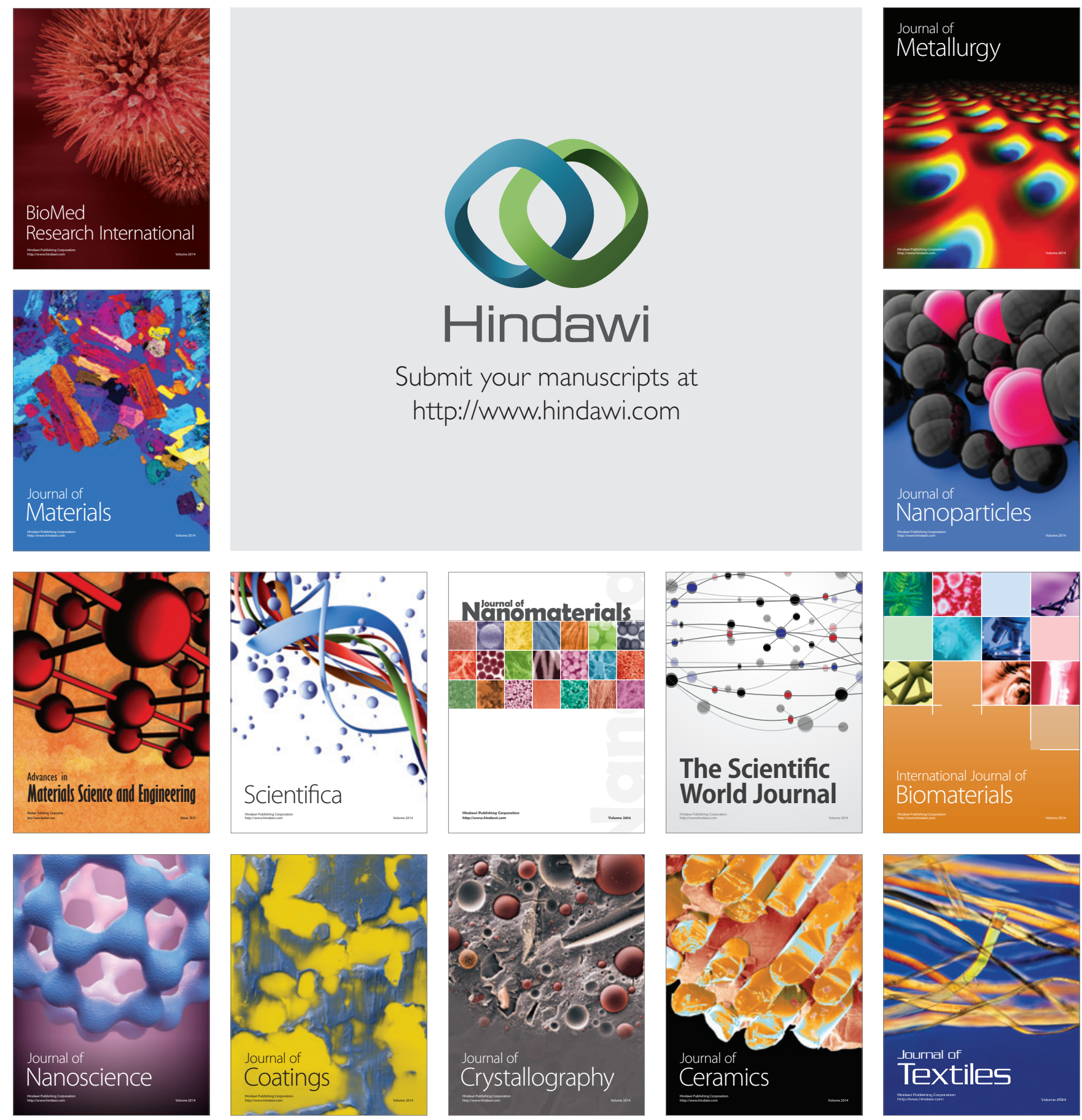